\title{
Editorial
}

The 20th anniversary of the International Society of Blood Purification (ISBP) is celebrated with the annual meeting taking place in Celle, Germany.

The ISBP was founded in the year 1982 by leading nephrologists to create an international forum for basic scientists and clinical researchers from universities and laboratories of the dialysis industry to present and discuss new developments and studies in the field of blood purification. The first annual meeting was organized by Prof. C.A. Baldamus in Frankfurt a.M., Germany in 1983, and in the year 2002, after having travelled around the world for two decades, the 20th annual meeting of the ISBP returns to Germany, this time to Celle, a former royal residence in Lower Saxony, close to Hannover.

Over the last 20 years, major improvements in the treatment of end-stage renal failure have been achieved including technical aspects (such as water treatment, dialysate composition and preparation, biocompatible dialyzer membranes, convective and online treatment modalities) as well as drug treatment (e.g. erythropoietin). Today, complications of cardiovascular diseases and infections are still the major causes of death in the dialysis population. In fact, cardiovascular mortality in dialysis patients is 20-fold higher compared to age-matched controls without renal insufficiency. This is the reason why the scientific program of the 20th annual meeting of the ISBP focuses on seminars entitled 'Cardiovascular disease and risk factors in uremia' and 'Infection and immunity in uremia' with invited lectures by leading experts. Another highlight is the presentation of this year's recipient of the ISBP award. Prof. Peter J. Ratcliffe gives a lecture entitled: 'From erythropoietin to oxygen: hypoxia-inducible factor hydroxylases and the hypoxia signal pathway'. The scientific program is completed by a panel discussion on 'Toxicity of perfluorocarbon in hemodialysis', three sessions of free communications and four parallel sessions of guided poster presentations.

This special issue of the journal Blood Purification contains the ISBP award lecture, twelve invited lectures and all abstracts accepted for oral or poster presentation.

On behalf of the organizing committee of the 20th annual meeting of the ISBP, I thank all the invited speakers and colleagues who submitted abstracts for their valuable contributions. Together we have succeeded in organizing a scientific program of extraordinary quality which should attract many interested scientists and nephrologists, and stimulate fruitful discussions.

\section{Gerhard Lonnemann}

President of the 20th Annual Meeting of the International Society of Blood Purification

\footnotetext{
KARGER

(C) 2002 S. Karger AG, Basel

Fax +4161306 1234

E-Mail karger@karger.ch

www.karger.com

Accessible online at:

www. karger.com/journals/bpu
} 